\title{
Growth of the Rat Somatic Sensory Cortex and Its Constituent Parts during Postnatal Development
}

\author{
David Riddle, Ann Richards, Feri Zsuppan, and Dale Purves \\ Department of Neurobiology, Duke University Medical Center, Durham, North Carolina 27710
}

\begin{abstract}
We have compared the size and arrangement of the primary somatic sensory cortex (SI) and its constituent parts in juvenile ( 1 week old) and mature (10-12 weeks old) rats using succinic dehydrogenase histochemistry and digital image analysis. Our goal was to determine whether some regions of the maturing cortex grow more than others. To this end, we examined (1) the growth of barrels and the surrounding (interbarrel) cortex, (2) the growth of the major somatic representations within SI, and (3) the overall growth of SI compared to the neocortex as a whole.

With respect to the first of these issues, SI barrels and barrel-like structures grow more than the intervening cortex. The growth of these elements varies according to region: barrels in the head representation more than double in size, whereas the barrel-like structures in the paw representations increase by only about half this amount. The growth of the major somatic representations within $\mathrm{SI}$ is also heterogeneous, the representation of the head enlarging to a greater extent than the representations of the paws. Thus, the ratio of the total area of head representation to the combined paw representation is $15 \%$ greater in adults than in juveniles. Finally, the primary somatic sensory cortex grows to a somewhat greater extent than the neocortex as a whole.

These observations demonstrate that postnatal cortical growth is not uniform; it varies among cortical barrels and the immediately surrounding (interbarrel) cortex, among the representations of different body parts, and between $\mathrm{SI}$ and the rest of the neocortex. As an explanation of this differential growth, we suggest that the neuropil of metabolically (and/or electrically) more active cortical regions grows to a greater extent during maturation than that of less active regions.
\end{abstract}

A remarkable feature of postnatal brain development is the degree of ongoing growth. The human brain increases in weight from an average of $350 \mathrm{gm}$ in newborns to $1400 \mathrm{gm}$ in adult males (Pakkenberg and Voigt, 1964; Dekaban and Sadowsky, 1978). This degree of postnatal brain growth is not limited to man. The average weight of the rodent brain, for example, also increases by about a factor of 4 during postnatal maturation

\footnotetext{
Received Dec. 23, 1991; revised Feb. 28, 1992; accepted Mar. 31, 1992

We are grateful to Marybeth Groelle for her steadfast help, and to David Fitzpatrick, Jon Kaas, Larry Katz, Herb Killackey, and Anthony LaMantia for valuable criticism of the manuscript. We also thank Don Burdick for his advice about the statistical aspects of the work.

Correspondence should be addressed to David R. Riddle, Department of Neurobiology, Box 3209, Duke Inniversity Medical Center, Durham, NC 27710.

Copyright (C) 1992 Society for Neuroscience $0270-6474 / 92 / 123509-16 \$ 05.00 / 0$
}

(Pomeroy et al., 1990; see also Results). Despite the relevance of ongoing brain growth to the development of complex behavior and the long-term storage of information, relatively little attention has been paid to this phenomenon.

In the present work, we have focused on the rat primary somatosensory cortex $(\mathrm{SI})$ and its component parts as a relatively simple system in which to explore quantitatively the postnatal growth of the cerebral cortex. Some 15 years ago, Rice and Van der Loos (1977) reported that the cortical specializations related to mystachial vibrissae in the mouse grow to a greater extent than does the rest of the neocortex. More recently, Johnson (1990) has reviewed observations that may indicate differential growth in the somatic sensory cortex of a variety of other mammalian species. Using succinic dehydrogenase (SDH) histochemistry and image analysis, we have examined differential growth of the rat cortex at three different levels. First, we compared the growth of barrels and barrel-like structures within SI to the growth of the adjacent, interbarrel regions. Second, we compared the relative growth of five well-demarcated representations within the primary somatic sensory cortex. Finally, we compared the overall growth of SI to the growth of the neocortex as a whole. Our results show that the cortex does not expand symmetrically; rather, it is subject to small, but highly signifcant, differences in regional growth. In general, the areas that grow most during postnatal life appear to be those that stain most intensely for enzymes that reflect cortical metabolism.

\section{Materials and Methods}

Animals. Sprague-Dawley rats were obtained from Harlan SpragueDawley (Indianapolis, IN); only males were used to avoid variation arising from gender. For observations in 1-week-old animals, litters were culled to eight pups on the first postnatal day (PNI; day of birth $=$ PNO). Adult males were examined at 10-12 weeks of age. One-weekold animals were chosen as the starting point for our study because the somatotopic map is fully formed by this age (Belford and Killackey, 1980; Rice, 1985; Rice et al., 1985; Dawson and Killackey, 1987), yet the cortex continues to grow substantially (see Results). The rat was chosen because the somatic sensory map in this species is well demarcated by SDH histochemistry, allowing precise measurement of cortical areas. Each animal was weighed, deeply anesthetized with sodium pentobarbital $(250 \mathrm{mg} / \mathrm{kg}$, i.p.), and perfused through the heart with physiological saline at room temperature $(10 \mathrm{ml}$ for juveniles and $60 \mathrm{ml}$ for adults). This procedure was followed by perfusion with $10 \%$ glycerol in distilled water $(30 \mathrm{ml}$ for juveniles and $120 \mathrm{ml}$ for adults). Brains were removed, blotted, and weighed to the nearest $10 \mathrm{mg}$. They were then rapidly frozen in methylbutane cooled to $-40^{\circ} \mathrm{C}$ with dry ice, with or without dissection and flattening of the cerebral cortex (see below). Brains that could not be sectioned on the day of death were stored in sealed containers at $-70^{\circ} \mathrm{C}$. Despite the use of male animals of defined age from litters culled to a standard number, we found a considerable range of brain size at the same age (Fig. 1). It was therefore necessary to examine a large sample at each age.

Visualization of the somatic map. In order to measure SI and its 


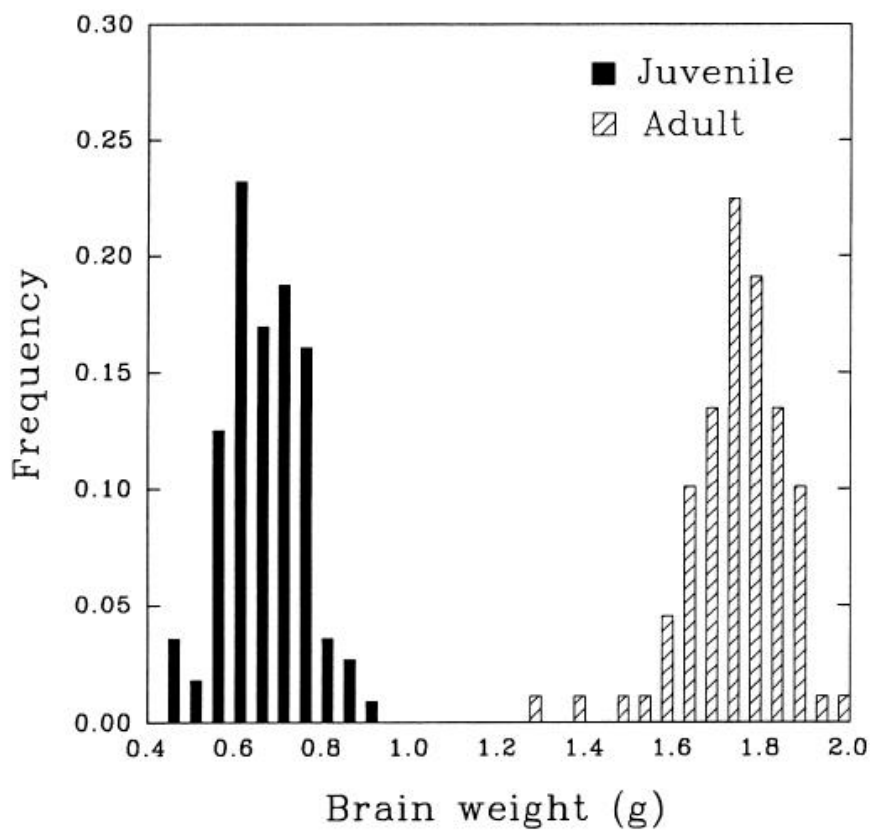

Figure 1. Brain size (by weight) in juvenile and adult rats. Mean brain weight increased from $0.69 \pm 0.02 \mathrm{gm}$ in 1 -week-old animals $(n=112)$ to $1.74 \pm 0.01 \mathrm{gm}$ in adults ( $n=89$; a 2.5 -fold increase). Body weight increased from an average of $16.9 \pm 0.5 \mathrm{gm}$ in 1-week-old animals to $332 \pm 8 \mathrm{gm}$ in adults (a 20 -fold increase). The variance of brain size in each population, which is presumably reflected in the size of cortical areas such as SI, makes the analysis of large samples necessary.

constituent parts, the cortical mantle was removed and flattened between Teflon-coated glass slides to a thickness of exactly $2 \mathrm{~mm}$ before freezing. Serial tangential sections were cut in a cryostat at $50 \mu \mathrm{m}$ and stained for SDH to reveal the primary somatic sensory map (Nachlas et al., 1957; Killackey and Belford, 1979; Dawson and Killackey, 1987; Wallace, 1987). Sections were dried on the slides at $37^{\circ} \mathrm{C}$ for $30 \mathrm{~min}$, fixed in phosphate-buffered $10 \%$ formalin $\left(\mathrm{pH} \mathrm{7.6)}\right.$ at $4^{\circ} \mathrm{C}$ for $1 \mathrm{~min}$, rinsed in distilled water, and then reacted at $37^{\circ} \mathrm{C}$ for $35-50 \mathrm{~min}$ in 0.05 M sodium succinate and $0.55 \mathrm{~mm}$ nitroblue tetrazolium in $0.05 \mathrm{M}$ phosphate buffer $(\mathrm{pH} 7.6)$. The slides were rinsed again in distilled water and coverslipped with Aqua-Mount (Lerner Laboratories, Pittsburgh, PA).

The growth of SI and its constituent parts was determined by comparing average values in cohorts of juvenile and adult animals. It was important, therefore, to determine the degree to which cortical area was altered by the flattening procedure in the two populations. For this purpose, pledgets of Whatman \#3 filter paper approximately the size of SI were labeled with India ink and applied to the frontoparietal cortex for $5 \mathrm{sec}$. The cortex was then removed and flattened, and the marked area compared to the actual size of the ink-soaked paper (Fig. 2). Flattening the cortex in juvenile (1-week-old) animals resulted in a $5 \%$ increase in the stained area, on average; a $6 \%$ increase was observed in adults (Table 1). As these differences are small and not significantly different in juvenile and adult populations, uncorrected values of map areas are used throughout our report.
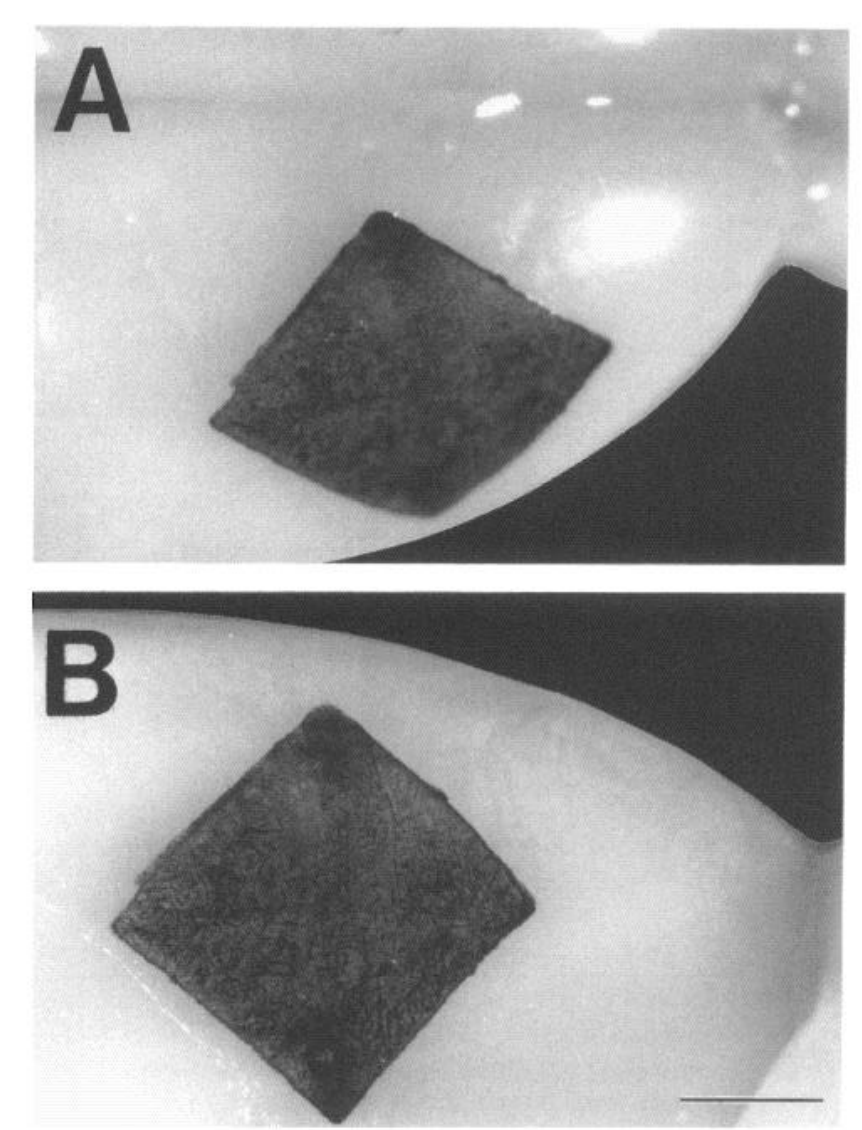

Figure 2. Control experiment to evaluate the effect of flattening on the area of SI and the neocortex as a whole. $A$, A pledget of filter paper was soaked in India ink and placed briefly on the cortical surface, leaving a well-defined mark of known dimensions in the region of SI. The average size of the mark was approximately the area of SI (compare Tables 2, 9). B, The cortex was then flattened and frozen (see Materials and Methods), and the India ink-stained area measured. The average change in size of the marked area with flattening was small (5-6\%) and not significantly different in juvenile and adult animals (Table 1). Scale bar, $10 \mathrm{~mm}$.

Measurement of SI and its constituent parts. Barrels and barrel-like structures stained by SDH histochemistry (Fig. 3) were used (1) to identify the major representations within the primary somatic sensory cortex (Fig. 4), (2) to define for measurement each of the major representations within SI (Fig. 5), and (3) to define for measurement the area occupied by SI as a whole (Fig. 6). Specific barrels were also used as points of reference for linear measurements of SI (see Table 7, Fig. 11).

Two-dimensional maps of the flattend somatic sensory cortex were traced from tangential sections at a final magnification of $28 \times$ using a camera lucida. Radial blood vessels and barrels that appeared in multiple sections were used to align precisely the 4-12 sections compiled for each complete map. The completed somatic sensory map was then digitized for detailed measurements using an NC-70D video camera (Dage MTI, Michigan City, IN) (Fig. 4A); image processing and analysis

Table 1. Effects of cortical flattening determined empirically by measurement of an area marked with India ink

\begin{tabular}{llllll} 
& $\begin{array}{l}\text { Number of } \\
\text { hemispheres } \\
\text { examined }\end{array}$ & $\begin{array}{l}\text { Average size } \\
\text { of ink-soaked } \\
\text { paper }\left(\mathrm{mm}^{2}\right)\end{array}$ & $\begin{array}{l}\text { Average size } \\
\text { of ink mark } \\
\text { after cortical } \\
\text { flattening }\end{array}$ & $\begin{array}{l}\text { Average } \\
\text { \% change }\end{array}$ & $\begin{array}{l}\text { Average } \\
\text { correction } \\
\text { factor }\end{array}$ \\
\hline Juveniles & 39 & $12.3 \pm 0.3$ & $12.8 \pm 0.3$ & $4.5 \pm 0.9$ & $0.96 \pm 0.01$ \\
Adults & 28 & $21.0 \pm 0.6$ & $22.1 \pm 0.6$ & $6.0 \pm 1.1$ & $0.95 \pm 0.01$ \\
\hline
\end{tabular}


were carried out using IMAGE 1/AT software (Universal Imaging Inc. West Chester, PA).

Five major representations are readily recognized within SI by the arrangement of SDH-positive barrels and barrel-like structures: the whisker pad (also called the posterior medial barrel subfield or PMBSF) the anterior snout, the lower jaw, the forepaw, and the hindpaw (Fig. $4 B$; see also Fig. 3). Each of these regions, and SI as a whole, was outlined according to the definitions given in Figures 5 and 6 . We then determined the average barrel size for each representation, the sum of the barrel and interbarrel areas for each representation, the total barrel and interbarrel area for SI as a whole, the area of each representation, and the overall area of SI. This analysis was facilitated by IMAGE 1 programs created for each acquisition and measurement task.

A potential problem in our measurements is the relatively better definition of barrels in the head representations compared to the analogous structures in the paw representations (see Fig. 3). The somewhat weaker staining of barrel-like structures in the paw representations made the assignment of barrel and interbarrel cortex more difficult. It seems reasonable to presume, however, that any such errors would have occurred equally in juvenile and adult brains.

Measurement of neocortical area. To determine the surface area of the neocortex, hemispheres from glycerol-perfused juvenile and adult rats were frozen intact, cut coronally at $50 \mu \mathrm{m}$ in a cryostat, and stained for SDH as described. The linear extent of neocortex was measured in camera lucida tracings of every fifth section using a digital planimeter and morphometric software (BIOQUANT IV, R\&M Biometrics Inc., Nashville, TN). The neocortex in each section was defined as extending from the rhinal fissure laterally to the termination of the cingulate cortex on the medial surface of the hemisphere (see Fig. 13). Alternate sections stained with cresyl violet were examined to ensure accurate assessment of these cortical boundaries. The area of the neocortex was calculated using the equation $S=s\left[1 / 2\left(Y_{1}+Y_{n+1}\right)+Y_{2}+Y_{3}+\ldots+Y_{n}\right]$, where $S$ is the surface area of the neocortex, $s$ is the interval between sections examined $(0.25 \mathrm{~mm})$, and $Y_{1}, Y_{2}, Y_{3}, \ldots Y_{n}$ are the surface lengths of the neocortex measured in each of the sections examined (Tuttle and Satterly, 1925). The accuracy of this method was checked empirically by applying India ink-soaked pledgets of known size to the cortex before freezing (see above). The linear extent of the ink-stained region was then measured in coronal sections, and the area calculated according to the method just described; this value was then compared to the actual size of the pledget. This control showed that our calculation slightly overestimates the area of the neocortex in both juvenile and adult animals (Table 2). As there was no significant difference between the small overestimation of both neocortical area and SI area (compare Tables 1, 2), measurements of SI and the neocortex are compared without correction.

Statistics. Since it is not possible to make measurements in the same rats at different ages, we necessarily used separate populations to determine juvenile and adult values (reported as means \pm standard error of the mean). By comparing the mean area of a region of interest in juvenile and adult populations, we could readily estimate the areal growth of that region and assess whether the change was statistically significant (a one-tailed Student's $t$ test was used routinely). We could also estimate the relative growth of any two regions by comparing the percentage change in the area of one region to the percentage change in the area of another region. Such percentage estimates cannot, however, be evaluated statistically. Furthermore, there is no legitimate way to pair individual juvenile and adult values. For statistical analysis of the relative growth of any two regions within SI, therefore, we calculated the ratio of the areas of the two regions of interest in each hemisphere and then determined the mean ratios in the juvenile and adult populations. These means could be compared by Student's $t$ test. In addition to permitting statistical evaluation, the use of ratios obviates any abiding concern about the effects of flattening or other technical problems that might affect each brain somewhat differently.

Analysis of the growth of SI relative to the growth of the neocortex as a whole was more problematic since the area of SI and the area of neocortex had to be measured in different hemispheres. Given four independently derived means (the area of SI in juveniles and adults, and the area of the neocortex in juveniles and adults), comparing the difference between two of the means (SI areal change) to the difference between the remaining two (neocortical areal change) presents an intractable problem in terms of statistical verification. In a subset of 21 juvenile and 25 adult animals, therefore, we determined the area of SI in the (flattened) cortex of one hemisphere and measured the area of the neocortex in the contralateral hemisphere; the ratio of the area of SI to the area of the contralateral neocortex was then calculated for each animal. Differences in the mean ratios in juvenile and adult rats could then be evaluated statistically.

\section{Results}

\section{Barrels and barrel-like structures in SI}

Barrels were first observed in layer IV of the rodent cortex about 70 years ago (Lorente de No, 1922). In general, subsequent work on the rodent somatic sensory system has focused on a subset of these structures related to the mystachial vibrissae (Woolsey and Van der Loos, 1970; Woolsey et al., 1981; Killackey, 1983; Woolsey, 1985); indeed, the term "barrel" was coined in this context and has become synonymous with the layer IV cortical representations of mystachial vibrissae.

More recently, barrels have been defined by the distribution of thalamocortical afferents (Jensen and Killackey, 1987) and by enzyme histochemistry (Wong-Riley and Welt, 1980; Dawson and Killackey, 1987; Wallace, 1987). Moreover, barrel-like structures, some of which are unrelated to hairs, have been found widely in SI (Dawson and Killackey, 1987; Jensen and Killackey, 1987; Wallace, 1987; see also Welker, 1971, and below). An important question, therefore, is what the proper definition of "barrel" should now be, and for purposes of the present work, what structures are revealed by enzyme histochemistry. Detailed studies of cytochrome oxidase (CO) staining have shown that this technique labels reactive mitochondria in cortical neurons, particularly in dendrites (Wong-Riley, 1989). Although ultrastructural evidence is lacking, SDH (another mitochondrial enzyme) presumably has a similar distribution. Taken together,

Figure 3. Tangential section $(50 \mu \mathrm{m})$ through the layer IV of the primary somatic sensory cortex of a 1-week-old male rat, stained by SDH histochemistry (see Materials and Methods). A, Low-power view showing SI map in relation to flattened cortex as a whole (anterior is to the right: ventral is up). The hindpaw representation is absent because even after flattening there is still a slight curvature that tends to prevent inclusion of the entire map in any single section. Accordingly, we routinely compiled 4-10 such sections in juveniles and 4-12 such sections in adults to reconstruct $S I$ in its entirety. $B$, Higher-power photomontage showing the complete SI map in this animal. The section has been rotated to the orientation used in all subsequent figures. As suggested in this example, barrels in the head representations stained somewhat more intensely than those in the paw representations, and barrels in the forepaw representation tended to stain more strongly than those in the hindpaw representation. Scale bars: $A, 2 \mathrm{~mm} ; B, 1 \mathrm{~mm}$.

Figure 4. Coding the somatic map for computer analysis. A, After tracing the complete set of barrels in SI by camera lucida, the map was digitized with a video camera. The image was then thresholded, and the outline of each barrel thinned to a uniform, single-pixel thickness. The representation of the trunk is also outlined here to show its position in relation to the other SI representations; the trunk representation was not, however, routinely analyzed because it is imprecisely defined. Barrels lateral and posterior to the PMBSF ( $P P M B S F)$ were not included in the subsequent analysis. Designations such as lateral, posterior, and so on, refer to the actual position within the cortex (rather than to the somatopic representation per se). $B$, The barrels in each of the five major regions in the somatic representation (the PMBSF, the anterior snout, the lower jaw, the forepaw, and the hindpaw) were then coded by gray levels for subsequent analysis. Scale bars, $2 \mathrm{~mm}$. 

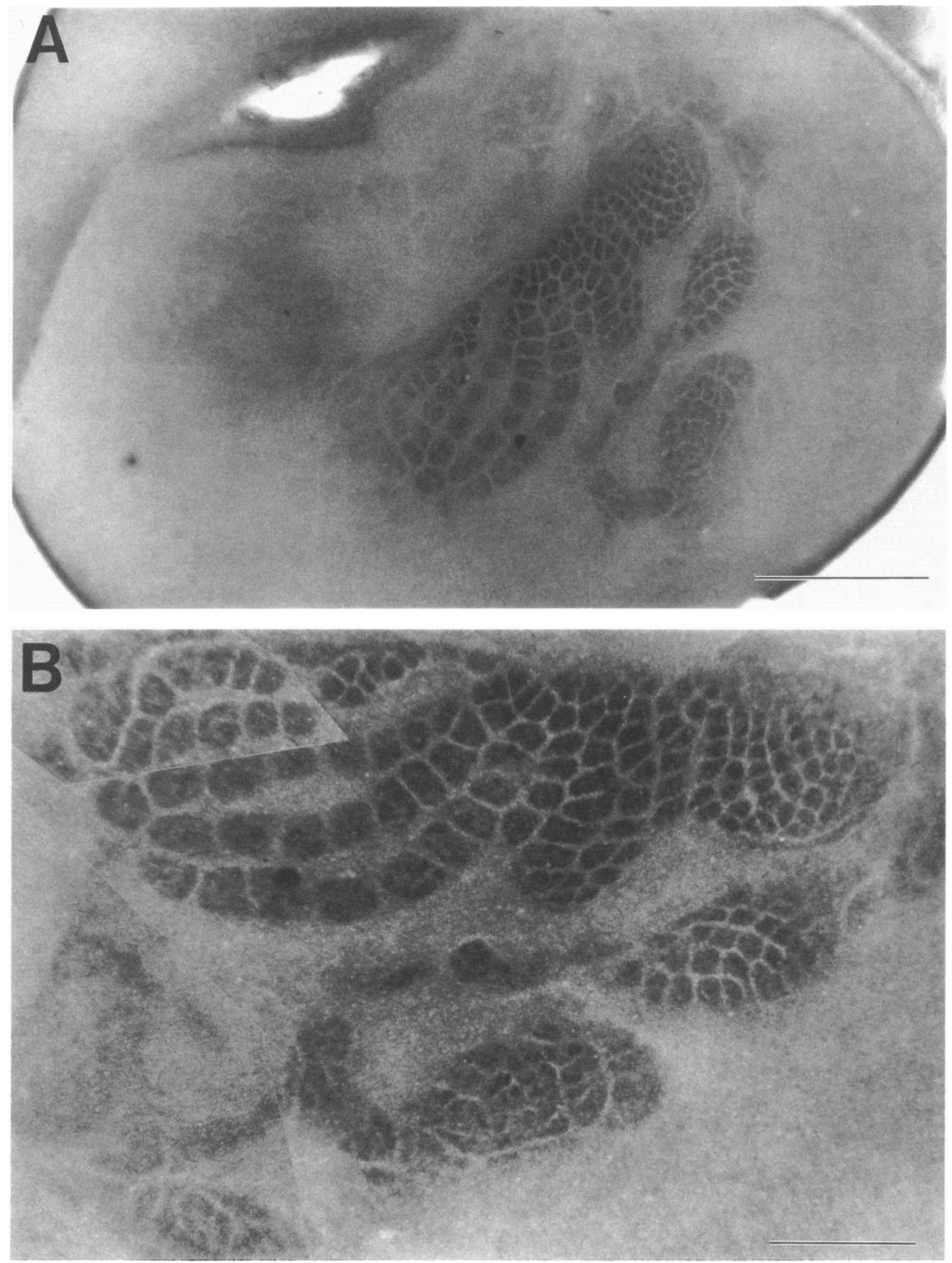

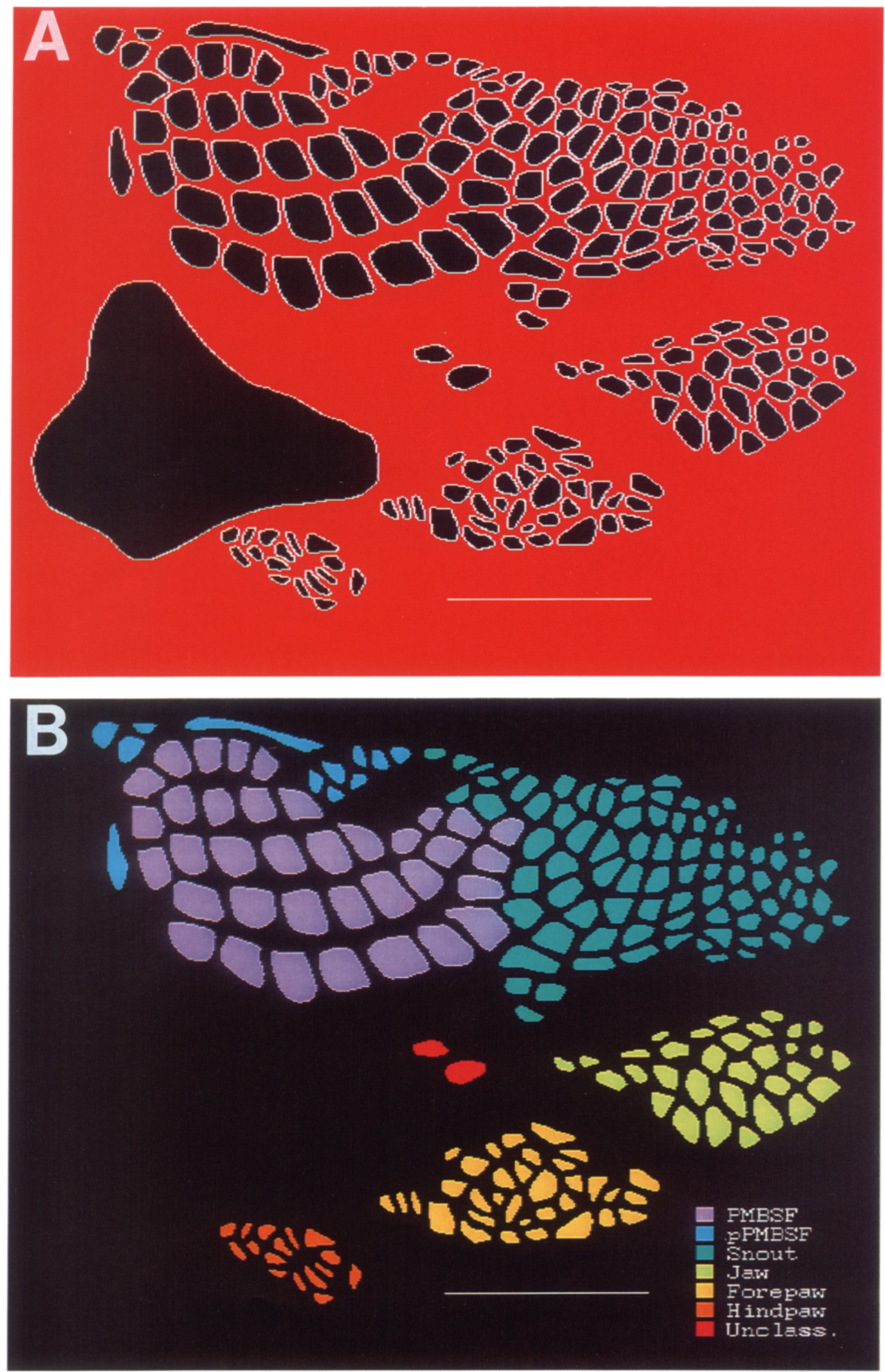

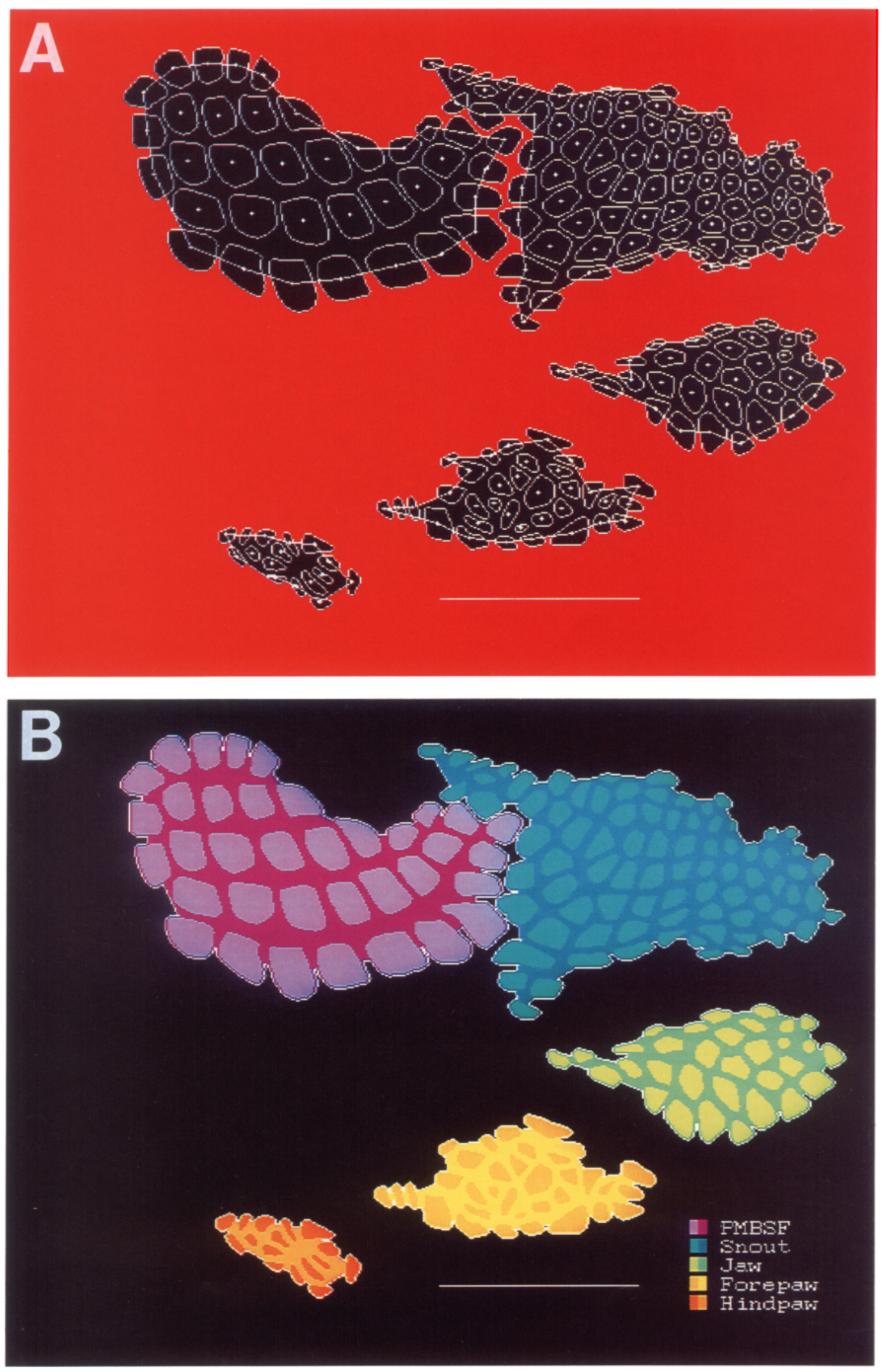


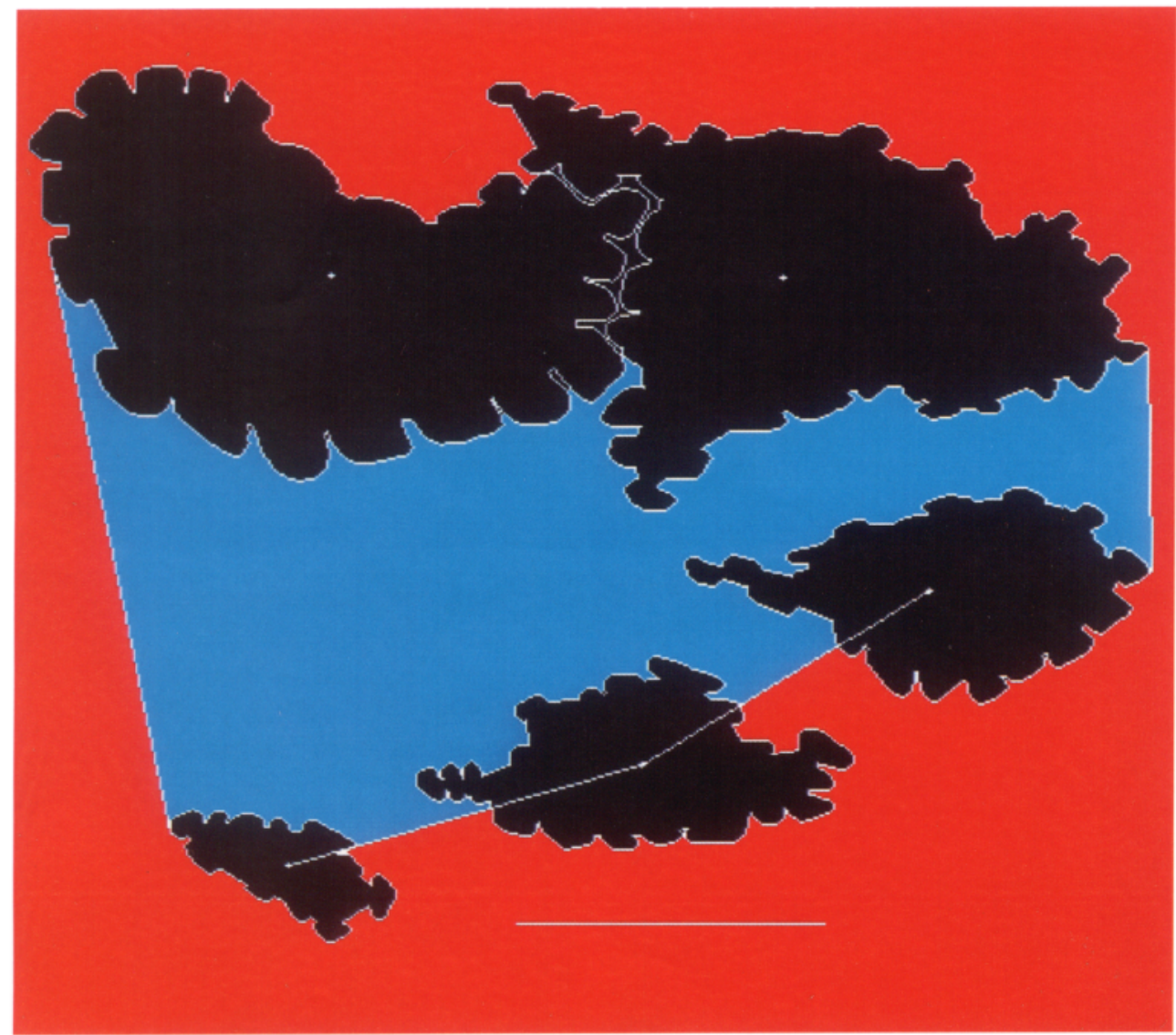

Figure 6. Definition of the primary somatic sensory cortex. For the purposes of the present study, SI as a whole was defined by (1) the lateral boundary of the head representations, (2) a line between the most posteromedial barrel in the PMBSF and the most posterior barrel in the hindpaw, (3) the medial boundaries of the paw representations and a line between the centroids of the hindpaw and forepaw regions, (4) a line between the centroids of the forepaw and lower jaw representations, and (5) the anterior boundary of the lower jaw representation and a line between the most anterior barrel in the lower jaw representation and the most anterior barrel in the head representation. This outline does not correspond exactly to the outline of SI revealed by SDH (or by electrophysiology; Welker, 1971; Kaas, 1983; Killackey, 1983; Welker et al., 1984). In particular, it excludes the most posterior portion of the trunk representation (compare Figs. 3, 4A). We nonetheless chose this definition because it can be exactly applied in every animal, and because it encompasses the vast majority of SI defined anatomically and electrophysiologically. The overall area of SI was measured by filling in this outline. The area of the nonbarrel cortex within SI (blue) was defined as the area of SI minus the sum of the areas of the major somatic representations. Scale bar, $2 \mathrm{~mm}$.

these several observations indicate that each barrel represents a complex layer IV processing unit defined by a selective distribution of thalamic afferents, a metabolically distinct set of postsynaptic cells, and in at least the better-developed barrels in SI, a corresponding cytoarchitecture (see Fig. 7).

To confirm that SDH histochemistry is a valid measure of barrels defined in this way, we examined alternate tangential sections stained for $\mathrm{CO}$ cell bodies and SDH (Fig. 7). Throughout SI, SDH-stained structures corresponded precisely with COstained structures, and with the cytoarchitectonic boundaries of barrels defined by conventional Nissl staining. We noted no obvious difference in the appearance or congruity of the barrels related to the mystachial vibrissae and barrel-like structures elsewhere in SI (other than the somewhat poorer definition by all of these methods of the barrel-like structures in the paw representations). It seems reasonable, therefore, to consider all of the SDH-stained structures in SI as generally similar elements reflecting peripheral sensory specializations. Indeed, recent mapping of the paw representations suggests that the barrel-like structures in these cortical areas correspond to specific parts of the paws (Dawson et al., 1987). Nonetheless, we distinguish throughout this report barrels in the PMBSF, and barrel-like structures elsewhere in SI. For the sake of economy, however, we use the term barrel in an inclusive sense in tables, captions, and headings to indicate not only the layer IV specializations associated with the mystachial vibrissae, but the similar layer IV specializations found throughout the primary somatic sensory cortex.

\section{Number and arrangement of barrels during maturation}

All the measurements made in this study depend upon the landmarks provided by the barrels and barrel-like structures of the five major representations within SI. Accordingly, we first examined the number and arrangement of barrels in juvenile and adult animals to ascertain whether this population is a stable one.

The overall number of barrels and barrel-like structures in SI was not significantly different in juveniles and adults (Table 3). Thus, the complete set of about 186 adult SI barrels is present from the end of the first postnatal week, at least as revealed by SDH histochemistry. Other barrel-like structures were present in SI but lay outside the standard representations that we analyzed (see Figs. 3-5; see also Dawson and Killackey, 1987; Wallace, 1987). In addition, numerous weakly stained and generally

Figure 5. Definition and measurement of the major somatic representations within SI. $A$, The borders of the each major representation within SI were determined by connecting the geometrical centers (centroids) of the barrels on the perimeter of each subregion, and then computing a border that included the outline of each barrel and the portion of the line between the centers of adjacent barrels. In calculating the overall area of each representation, the single-thickness border was divided equally between the representation and the surrounding cortex. $B$, For each of the five major representations within SI, barrel and interbarrel cortex were coded by assignment of different gray levels and measured. Since the barrel borders represent a true boundary, the borders (see $A$ ) were divided equally between barrel and interbarrel cortex in calculating the barrel and interbarrel areas for each representation. Scale bars, $2 \mathrm{~mm}$. 
Table 2. Comparison of areas of known size measured directly and calculated from linear measurements in serial coronal sections

\begin{tabular}{llllll} 
& $\begin{array}{l}\text { Number of } \\
\text { hemispheres } \\
\text { examined }\end{array}$ & $\begin{array}{l}\text { Average size } \\
\text { of ink-soaked } \\
\text { paper }\left(\mathrm{mm}^{2}\right)\end{array}$ & $\begin{array}{l}\text { Average } \\
\text { calculated } \\
\text { size of mark }\end{array}$ & $\begin{array}{l}\text { Average } \\
\text { \% change }\end{array}$ & $\begin{array}{l}\text { Average } \\
\text { correction } \\
\text { factor }\end{array}$ \\
\hline Juveniles & 29 & $12.5 \pm 0.3$ & $12.6 \pm 0.4$ & $2.7 \pm 2.3$ & $0.99 \pm 0.02$ \\
Adults & 27 & $21.1 \pm 0.6$ & $22.0 \pm 0.6$ & $4.9 \pm 1.3$ & $0.96 \pm 0.01$ \\
\hline
\end{tabular}

larger barrel-like structures were seen outside of SI, mostly in the secondary somatosensory cortex (SII; see also Koralek et al., 1990) (Fig. 8; see also Fig. 3A). Finally, the primary auditory cortex (AI) was apparent as a region of higher SDH reactivity in the cortex posterior and lateral to the PMBSF (see Fig. $3 A$ ); AI also contained barrel-like structures revealed by SDH staining.

\section{Growth of barrels in the plane of the cerebral cortex}

The size of barrels and barrel-like structures increases markedly during postnatal maturation. Considered as a single population, SI barrels increased in cross-sectional area by $88 \%$ (Table 4 ). This growth, however, varied greatly among the representations in SI. Barrels more than doubled in size within the somatic
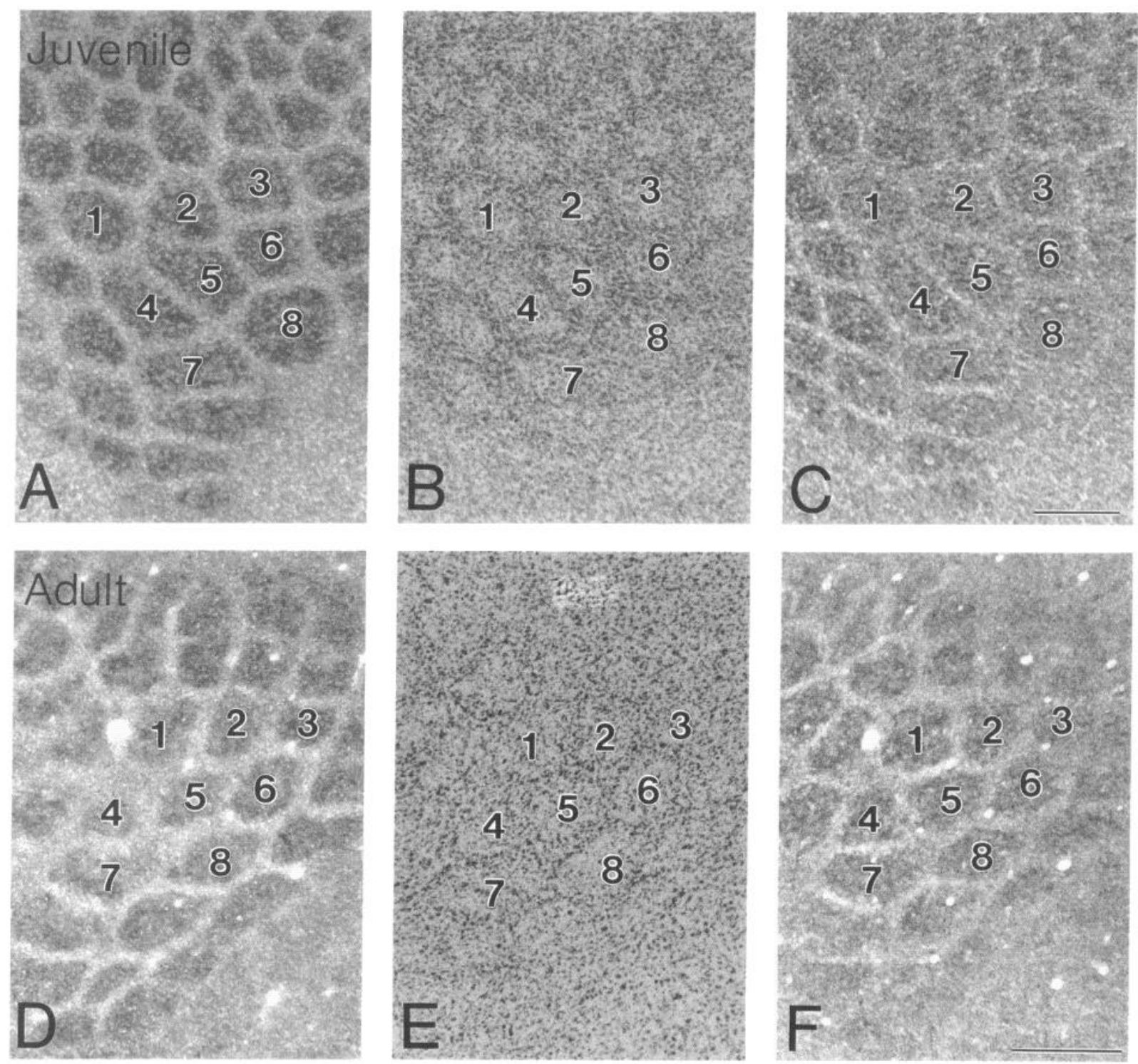

Figure 7. Correspondence of the enzymatic and cytoarchitectonic definitions of cortical barrels in juvenile (1-week-old) animals $(A-C)$ and adult (10-12-week-old) animals $(D-F) . A$ and $D$, Twenty-five micrometer cryostat sections of flattened cortex stained for SDH. Barrels shown are in the representation of the anterior snout. $B$ and $E$, Cytoarchitectonic definition of barrels in subjacent sections revealed by Nissl staining. $C$ and $F$, Sections adjacent to the ones shown in $B$ and $E$, stained for CO. Numbers indicate corresponding barrels in each of the three serial sections from the juvenile and adult cortices. Scale bars: $A-C, 250 \mu \mathrm{m} ; D-F, 500 \mu \mathrm{m}$. 
Table 3. Mean numbers of cortical barrels in SI and its major representations in juvenile and adult animals $(n=\mathbf{5 5}$ hemispheres in juveniles and 57 in adults)

\begin{tabular}{lcc} 
& Juvenile & Adult \\
\hline PMBSF $^{a}$ & 36 & 36 \\
Anterior snout & $82.4 \pm 1.0$ & $80.5 \pm 12.0$ \\
Lower jaw & $29.1 \pm 0.5$ & $29.3 \pm 0.5$ \\
Forepaw & $25.4 \pm 0.6$ & $27.3 \pm 0.6$ \\
Hindpaw & $11.8 \pm 0.3$ & $13.3 \pm 0.4$ \\
\multicolumn{1}{c}{ SI (total) } & $184.5 \pm 1.4$ & $186.3 \pm 1.7$
\end{tabular}

${ }^{a}$ Number of barrels is 36 by definition.

representation of the anterior snout, and doubled in the PMBSF and lower jaw representations (Fig. 9). However, barrel-like structures grew only about half as much in the paw regions. For example, in juveniles the mean cross-sectional areas of barrels in the lower jaw and hindpaw representations were approximately equal. In subsequent weeks, however, the barrels in the lower jaw representation doubled in size, whereas those in the hindpaw representation increased by only one-half. The greater growth of barrels in the head representation compared to the paws was confirmed statistically. Thus, the mean ratio of barrel size in the head representations to barrel size in the paw representations increased $28 \%$, from $1.51 \pm 0.05$ in juvenile animals to $1.94 \pm 0.06$ in adult animals $(p<0.0001)$.

\section{Gradient of barrel growth within the PMBSF}

In addition to comparing barrel growth among the different somatic representations of SI, we examined growth as a function of barrel size and position within the PMBSF (Fig. 10) (see also Rice and Van der Loos, 1977). Such detailed analysis is possible in the PMBSF because each barrel is uniquely identified. There was no significant difference between the growth of the largest and smallest barrels within the representation of the mystachial vibrissae (Fig. 10A). There was, however, a systematic tendency for barrels toward the anterior snout representation-whether large or small-to grow more than those in the more posterior portion of PMBSF (Fig. 10B,C). This anterior-posterior gradient may also be reflected in the slightly greater average growth of barrels in the anterior snout representation compared to those in the PMBSF (see Table 4).

\section{Growth of barrels in the radial dimension of the cortex}

To assess the radial growth of the somatic sensory cortex, coronal sections were taken through the anterior pole of the hip-

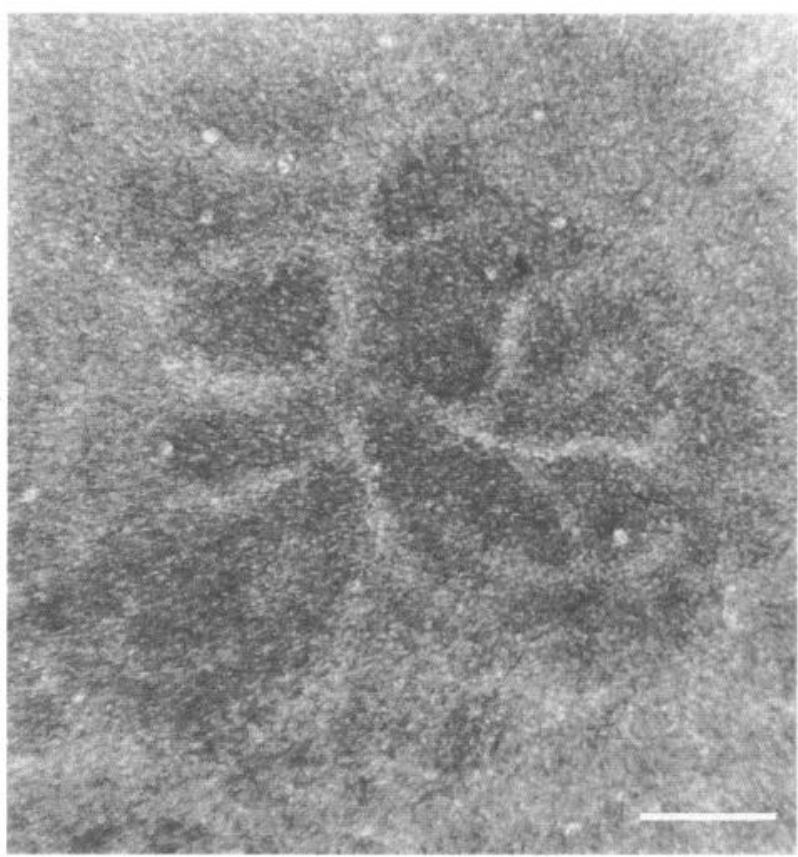

Figure 8. Barrel-like structures in the cortex surrounding SI. In al animals, a variable number of barrel-like structures were evident outside of the primary somatic sensory cortex, as defined by the major barrel representations (see Fig. 3A). Most of these barrels were located lateral to the anterior snout representation (Fig. $3 A$ ); this region is generally taken to be the secondary somatic sensory cortex in rodents (SII; Kaas, 1983; Killackey, 1983). The prevalence of barrel-like structures outside of SI implies that barrels do not specifically represent whiskers or even digital pads, but some more general phenomenon that, among other things, enhances the metabolic activity of discrete, iterated cortical units. Scale bar, $0.25 \mathrm{~mm}$.

pocampus (i.e., at the level of the PMBSF). In a single SDHstained section from each animal, camera lucida tracings were made of a $3 \mathrm{~mm}$ extent of cortex, including the barrels in layer IV. The cortical thickness (from the pial surface to the white matter) was measured at five equidistant points along this stretch and expressed as the mean of these values. Barrel height was taken as the average of five barrels measured in each section; the cross-sectional area of barrels in this plane was also measured.

Between 1 week and 10-12 weeks of age, cortical thickness in 25 juvenile and 25 adult brains increased from an average of $1.58 \pm 0.02 \mathrm{~mm}$ to $1.90 \pm 0.03 \mathrm{~mm}$, a $21 \%$ change. Barrel area in the coronal plane increased from $0.030 \pm 0.002 \mathrm{~mm}^{2}$

\begin{tabular}{|c|c|c|c|c|c|c|}
\hline & \multicolumn{3}{|c|}{ Average barrel area $\left(\mathrm{mm}^{2}\right)$} & \multicolumn{3}{|c|}{ Sum of barrel areas $\left(\mathrm{mm}^{2}\right)$} \\
\hline & Juvenile & Adult & $\begin{array}{l}\% \\
\text { Increase }\end{array}$ & Juvenile & Adult & $\begin{array}{l}\% \\
\text { Change }\end{array}$ \\
\hline PMBSF & $0.057 \pm 0.001$ & $0.112 \pm 0.002$ & 96 & $2.07 \pm 0.05$ & $4.04 \pm 0.08$ & 95 \\
\hline Anterior snout & $0.017 \pm 0.001$ & $0.036 \pm 0.001$ & 112 & $1.42 \pm 0.03$ & $2.90 \pm 0.06$ & 104 \\
\hline Lower jaw & $0.016 \pm 0.001$ & $0.032 \pm 0.001$ & 100 & $0.48 \pm 0.01$ & $0.94 \pm 0.02$ & 99 \\
\hline Forepaw & $0.024 \pm 0.001$ & $0.038 \pm 0.001$ & 58 & $0.60 \pm 0.02$ & $1.01 \pm 0.03$ & 68 \\
\hline Hindpaw & $0.014 \pm 0.001$ & $0.021 \pm 0.001$ & 50 & $0.17 \pm 0.01$ & $0.27 \pm 0.01$ & 59 \\
\hline SI as a whole & $0.026 \pm 0.001$ & $0.049 \pm 0.001$ & 88 & $4.74 \pm 0.11$ & $9.16 \pm 0.15$ & 93 \\
\hline
\end{tabular}


Figure 9. The growth of identified SI barrels between 1 and $10-12$ postnatal weeks. $A$, Specific barrels in the PMBSF (barrels $B 3-B 5, C 3-C 5, D 2-D 4$ ) in a representative juvenile (1-week-old) animal. $B$, The same set of barrels in a representative adult (11-week-old) animal. Scale bar, $0.5 \mathrm{~mm}$.
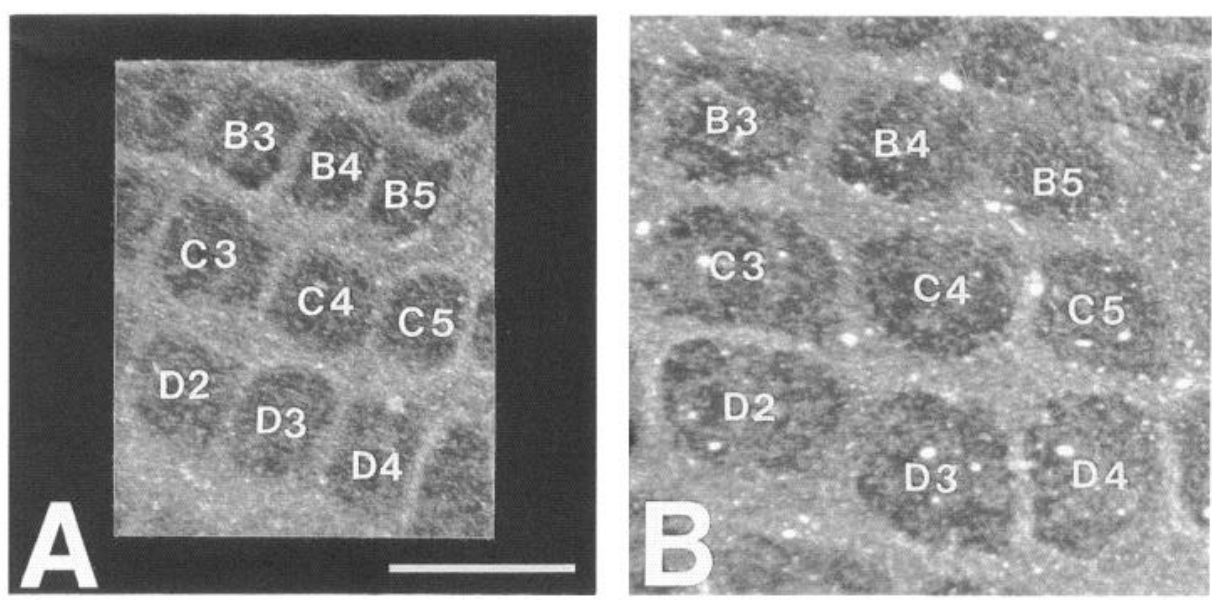

to $0.064 \pm 0.003 \mathrm{~mm}^{2}$, a $113 \%$ change; the average height of barrels increased from $0.170 \pm 0.005 \mathrm{~mm}$ to $0.273 \pm 0.006$ $\mathrm{mm}$, a $61 \%$ change. These changes are consistent with measurements of cortical and barrel growth in the horizontal plane.

\section{Growth of interbarrel cortex within the major SI representations}

For each somatic representation within SI, the interbarrel area was determined by subtracting the sum of the barrel areas from the overall area (Table 5; compare Tables 4,8). Considering all five representations within SI, the interbarrel area increased by $67 \%$ (Table 5) compared to $93 \%$ for barrels (Table 4 ). The overall ratio of barrel to interbarrel cortex in juvenile animals was $1.94 \pm 0.03$, and in adult animals, $2.27 \pm 0.04$, a $17 \%$ difference $(p<0.0001)$.

The disproportion between barrel and interbarrel growth varied among the five major representations within SI (Table 6). The ratio of barrel to interbarrel area increased significantly for the PMBSF and the anterior snout representations $(21 \%$ and $19 \%$, respectively; $p<0.0001)$. A smaller but still significant increase in this ratio was apparent in the lower jaw and forepaw regions. The only exception to the greater growth of barrel compared to interbarrel cortex was the representation of the hindpaw, in which the growth of the barrel-like structures was equal to the growth of the interbarrel area.

The growth of the nonbarrel SI cortex-defined as the overall area of SI minus the sum of the five major representations demarcated by barrels and barrel-like structures (see Fig. 6)was intermediate in magnitude between barrel and interbarrel growth. Thus, the nonbarrel SI cortex increased from an average of $5.31 \pm 0.13 \mathrm{~mm}^{2}$ in juveniles to $9.55 \pm 0.16 \mathrm{~mm}^{2}$ in adults, an $80 \%$ increase.

\section{Growth of the major representations within SI}

The overall area of the representations related to the head (whisker pad, anterior face, and lower jaw) grew more than the areas of the representations of the forepaw and hindpaw (Table 7 ). The combined areas of the head representations increased $88 \%$, from $6.03 \pm 0.12 \mathrm{~mm}^{2}$ in juveniles to $11.34 \pm 0.29 \mathrm{~mm}^{2}$ in adults. In contrast, the combined areas of the paw representations increased only $64 \%$, from $1.13 \pm 0.03 \mathrm{~mm}^{2}$ in juveniles to $1.85 \pm 0.05 \mathrm{~mm}^{2}$ in adults. The mean ratio of the total area of the head representation to the combined paw areas increased $15 \%$, from $5.48 \pm 0.15$ in juvenile animals to $6.30 \pm 0.16$ in adults $(p<0.001)$. Thus, some representations within SI grow significantly more during maturation than others.

We also measured the linear growth of SI along defined axes of the somatic representation (Fig. $11 A$, Table 8 , top). The axis corresponding to the anterior-posterior axis of the head representation increased to a greater degree than the vector from the head to the hindpaw. The distance from the Al barrel in the PMBSF to the tip of the snout representation increased $47 \%$ on average, whereas the distance from $\mathrm{Al}$ to the inferior margin of the hindpaw representation increased only $30 \%$. These differences were confirmed statistically; the mean ratio of the Alsnout vector to the A1-hindpaw vector was $1.26 \pm 0.01$ in juveniles, and $1.39 \pm 0.01$ in adults (a 10\% increase; $p<0.0001$ ).

Measurements of the distances between the centroids of the five major representations within the somatotopic map (Fig. $11 \mathrm{~B}$ ) corroborated the conclusion that the growth of SI is greatest along the anterior-posterior axis of the head representation and least along the axis from the PMBSF to the hindpaw (Table 8 , bottom). Thus, the distance from the centroid of the PMBSF to the centroid of the anterior snout representation increased approximately $41 \%$; in contrast, the separation between the centroids of the PMBSF and hindpaw increased only $24 \%$. The average ratios of these two vectors were $0.77 \pm 0.01$ in juveniles and $0.88 \pm 0.01$ in adults, a $14 \%$ increase $(p<0.0001)$. These observations accord with the areal measurements showing that growth is greatest in the representations of the head, least in the representations of the paws, and intermediate in "nonbarrel" SI cortex.

\section{The overall growth of SI and of the neocortex as a whole}

The overall area of the primary somatic sensory cortex in our total sample increased $83 \%$ from about $12.5 \mathrm{~mm}^{2}$ in 1-weekold animals to $22.8 \mathrm{~mm}^{2}$ in adults (Figs. 12, 13; Table 9). Measurements in serial sections of brains from 1-week-old and adult animals showed that the surface area of the neocortex increased $73 \%$, from about $108 \mathrm{~mm}^{2}$ in juveniles to $187 \mathrm{~mm}^{2}$ in adults. By this assessment, the overall growth of the primary somatic sensory cortex apparently exceeds the growth of the neocortex as a whole. To confirm this observation statistically (see Materials and Methods), in 21 juvenile and 25 adult animals we determined the ratio of the area of SI measured in one hemisphere to the area of the neocortex measured in the contralateral hemisphere. This ratio increased from $0.114 \pm 0.002$ in juveniles to $0.121 \pm 0.002$ in adults $(p<0.02)$. 
A

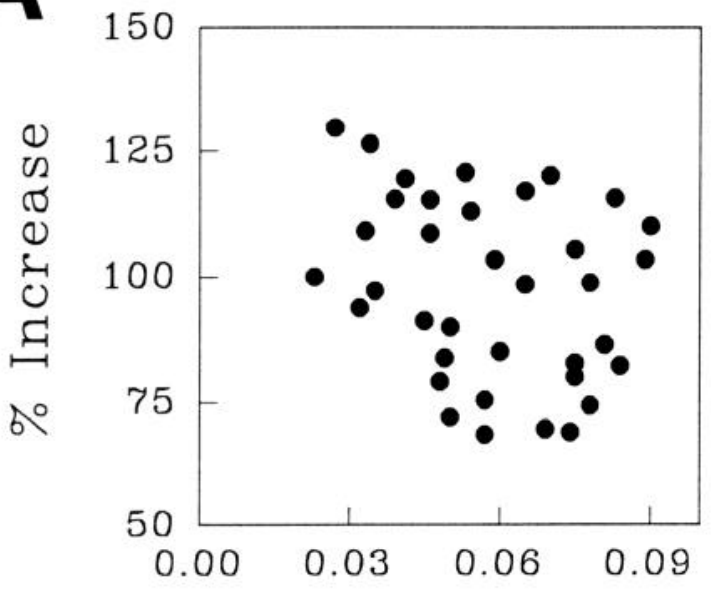

Barrel Area

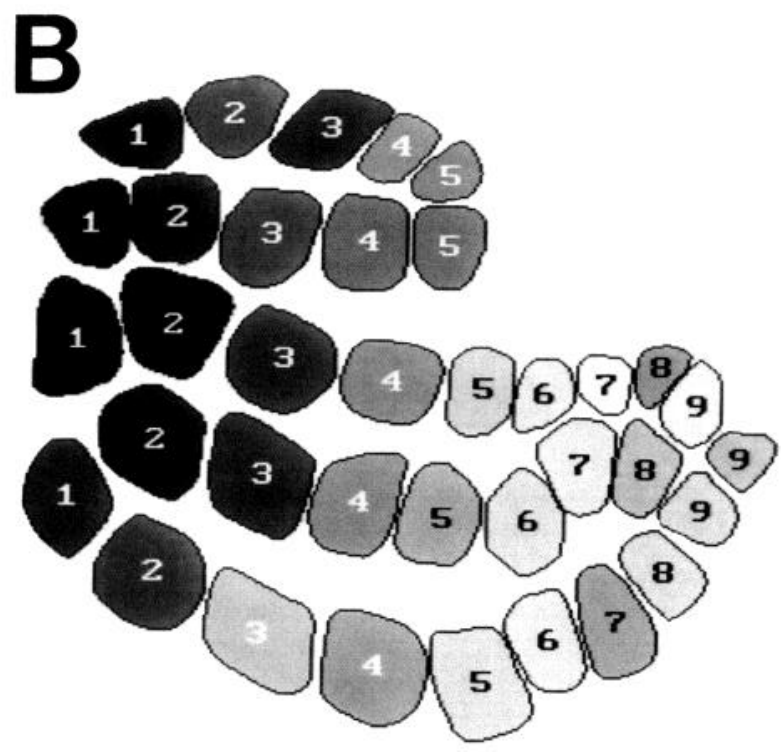

C

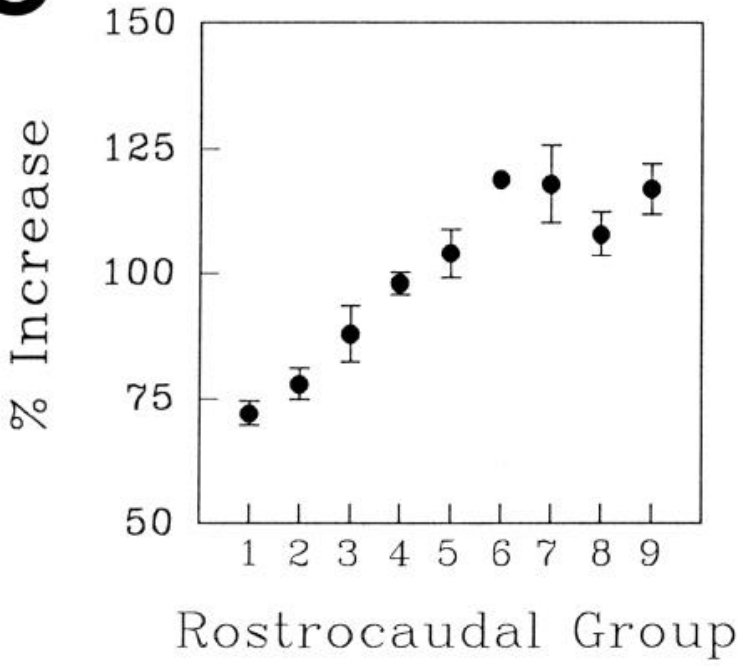

Table 5. Changes in the interbarrel area $\left(\right.$ in $\mathrm{mm}^{2}$ ) of the major representations within $\mathrm{SI}$ in juvenile and adult animals $(n=55$ hemispheres in juveniles and $\mathbf{5 7}$ in adults)

\begin{tabular}{llll} 
& Juvenile & Adult & $\%$ \\
\hline PMBSF & $0.96 \pm 0.03$ & $1.56 \pm 0.03$ & 62 \\
Anterior snout & $0.85 \pm 0.02$ & $1.46 \pm 0.04$ & 72 \\
Lower jaw & $0.25 \pm 0.01$ & $0.43 \pm 0.01$ & 72 \\
Forepaw & $0.32 \pm 0.01$ & $0.50 \pm 0.02$ & 55 \\
Hindpaw & $0.08 \pm 0.01$ & $0.14 \pm 0.01$ & 75 \\
$\quad$ Total, SI as a whole & $2.48 \pm 0.07$ & $4.10 \pm 0.09$ & 67 \\
\hline
\end{tabular}

\section{Discussion}

Despite the impressive degree of postnatal brain growth in mammals, little attention has been paid to the basis of this phenomenon or its functional significance. The issue of cortical growth is important for at least two general reasons. First, much adult behavior evidently depends on this phenomenon: interference with postnatal cortical growth (e.g., from malnutrition or thyroid insufficiency) leads to behavioral deficits and, in man, to mental retardation (Cravioto et al., 1966; Bedi and Warren, 1988; DeLong et al., 1989). Indeed, the area of the PMBSF is evidently reduced in malnourished mice (Vongdokmai, 1980). Second, experience during maturation is permanently stored within the brain. Given that brain growth is progressive, increasingly complex behavior-and progressively larger stores of informationmay depend upon a gradual accretion of connections that generates increasing combinatorial complexity; this accretive process would be reflected in the growth of neuropil and, ultimately, in the overall growth of the brain.

We have used the primary somatic sensory cortex and its component parts as a relatively simple system in which to explore postnatal cortical growth. The special advantage of SI in the rat is that it can be visualized by histochemical methods and measured precisely. Our results show that from the end of the first postnatal week to maturity (10-12 weeks of age), barrels and barrel-like structures grow more than the intervening cortical regions. Moreover, the growth of these elements varies among representations, and the growth of some somatic representations within SI exceeds the growth of others. Finally, the entire primary somatic sensory cortex - as a consequence of the differential growth of its constituent parts-grows to a somewhat greater extent than the neocortex as a whole.

\section{The differential growth of barrels}

The first level of our analysis examined barrel growth in SDHstained sections and compared it to the growth of interbarrel (and nonbarrel) SI cortex. Barrel and barrel-like structures in SI grow markedly in all regions, but most extensively in the PMBSF,

Figure 10. Barrel growth as function of size and position in the PMBSF. $A$, Barrel growth as a function of barrel size; there is no apparent correlation between the cross-sectional area of a barrel (measured in juvenile animals) and its growth (as indicated by the percentage increase in cross-sectional area during maturation). $B$, Growth of individual barrels in the PMBSF. The degree of growth for each barrel is indicated by its gray level, with the darkest barrels growing least and the lightest most. Numbers show grouping for the analysis in $C$. $C$, Barrel growth as a function of position along the anterior-posterior axis of the head representation. The degree of postnatal growth increases along this axis. 


$\begin{aligned} & \text { Table 6. Differences in the barrel : interbarrel areal ratio for the major representations of SI in } \\
& \text { juvenile and adult animals }(\boldsymbol{n}=\mathbf{5 5} \text { hemispheres in juveniles and } \mathbf{5 7} \text { in adults) }\end{aligned}$
\begin{tabular}{lllll} 
& Juvenile & Adult & \% Change & $p$ Value \\
\hline PMBSF & $2.16 \pm 0.04$ & $2.61 \pm 0.04$ & 21 & $\ll 0.0001$ \\
Anterior snout & $1.70 \pm 0.03$ & $2.03 \pm 0.04$ & 19 & $\ll 0.0001$ \\
Lower jaw & $1.96 \pm 0.05$ & $2.21 \pm 0.07$ & 13 & $<0.01$ \\
Forepaw & $1.92 \pm 0.05$ & $2.12 \pm 0.08$ & 10 & $<0.05$ \\
Hindpaw & $2.28 \pm 0.11$ & $2.21 \pm 0.08$ & -3 & 0.6 \\
SI is a whole & $1.94 \pm 0.03$ & $2.27+0.04$ & 17 & $\ll 0.0001$ \\
\hline
\end{tabular}

anterior snout, and lower jaw representations. Our measurements also showed that, on average, barrels grow to a greater extent than the adjacent interbarrel regions. The growth of the nonbarrel SI cortex (i.e., the SI regions defined by exclusion of the major representations demarcated by barrels) was intermediate between the growth barrel and interbarrel cortex.

The cellular elements responsible for this differential areal growth are presumably both pre- and postsynaptic (i.e., the axonal processes of thalamic afferents, the dendrites and axons of cortical neurons, the synaptic connections between them, and the associatcd glial cclls). In support of the inference that the growth of barrels represents primarily the growth of cortical neuropil, the dendrites of barrel neurons grow substantially during postnatal maturation and these processes extend preferentially within barrels (Greenough and Chang, 1988; Peinado and Katz, 1990). Moreover, the distribution of thalamic afferents in the adult rat corresponds to the full extent of barrels as revealed by SDH staining (Jensen and Killackey, 1987).

\section{The differential growth of the major representations within SI}

The next question we addressed was whether the representations of different body parts within SI grow uniformly. We first demonstrated that the overall number of barrels and barrel-like structures in the major representations within SI is about the same in juvenile and adult animals. It is unlikely, therefore, that any error was introduced by a gain or loss during maturation of any of these clements. We nonetheless found systematic differences in the growth of the cortical representations of the whisker pad, the anterior face, the lower jaw, forepaw, and hindpaw. The growth of the head representation is greatest, and that of the paw representations, particularly the hindpaw, is least. These conclusions were confirmed by comparison of ratios that could be evaluated statistically (see Materials and Methods).

Table 7. Differences in the average area of each of the major somatic representations (in $\mathrm{mm}^{2}$ ) within $\mathrm{SI}$ in juvenile and adult animals $(n=55$ hemispheres in juveniles and 57 in adults)

\begin{tabular}{llrl} 
& Juvenile & \multicolumn{1}{c}{ Adult } & $\begin{array}{l}\% \\
\text { Increase }\end{array}$ \\
\hline PMBSF & $3.04 \pm 0.07$ & $5.60 \pm 0.10$ & 84 \\
Anterior snout & $2.27 \pm 0.05$ & $4.36 \pm 0.10$ & 92 \\
Lower jaw & $0.73 \pm 0.02$ & $1.38 \pm 0.03$ & 89 \\
Forepaw & $0.92 \pm 0.03$ & $1.51 \pm 0.04$ & 64 \\
Hindpaw & $0.24 \pm 0.01$ & $0.41 \pm 0.02$ & 71 \\
$\quad$ Sum & $7.20 \pm 0.14$ & $13.26 \pm 0.22$ & 84
\end{tabular}

Although the apportioning of cortical area presumably owes more to phylogeny than ontogeny, these findings indicate that differential cortical growth contributes to the phenomenon of cortical overrepresentation, that is, to the disproportionate representation of some regions in cortical maps compared to others. The relatively large amount of Al devoted to analyzing sonar signals in echolocating bats, the large area of the primary visual cortex (VI) devoted to the macula in animals with high visual acuity, and the large amount of SI devoted to the analysis of information from the whiskers in rodents must be primarily the result of evolution. Nevertheless, differential cortical growth during postnatal development provides a means by which an individual animal's experience can affect the amount of brain devoted to different functional tasks.

\section{The growth of the somatic sensory cortex in relation to the neocortex as a whole}

A final question about cortical growth is whether the major regions of the brain (e.g., the various primary sensory cortices) grow equally, or whether appreciable differences exist in the degree of areal growth among these distinct areas. Our results show that the overall growth of SI, to a small but significant degree, exceeds the growth of the neocortex as a whole during postnatal life. Although other primary sensory cortices (AI, VI) are apparent in the rat as regions of slightly increased SDH staining, they are too poorly defined to compare quantitatively with SI. The apparently greater growth of SI compared to the

Table 8. Linear measurements (in $\mathrm{mm}$ ) of SI in juvenile and adult animals ( $n=55$ hemispheres in juveniles and 57 in adults)

$\begin{array}{ll} & \% \\ \text { Juvenile } \quad \text { Adult } \quad \text { Change }\end{array}$

Average linear dimensions of SI (see Fig. 11 $\mathrm{A}$ ): from center of barrel Al to

Anterior snout

$4.64 \pm 0.05$

$4.83 \pm 0.05$

$6.67 \pm 0.07$

Anterior jaw

$4.32 \pm 0.05$

$6.95 \pm 0.08$

Anterior forepaw

$3.69 \pm 0.04$

$6.08 \pm 0.07$

47

Inferior hindpaw

$4.80 \pm 0.05$

44 41

Average distances between the centroids of each of the major SI representations (see Fig. $11 B$ )

$\begin{array}{llll}\text { PMBSF-anterior snout } & 2.09 \pm 0.02 & 2.95 \pm 0.03 & 41 \\ \text { Anterior snout-jaw } & 1.37 \pm 0.02 & 1.92 \pm 0.03 & 40 \\ \text { Jaw-forepaw } & 1.38 \pm 0.03 & 1.88 \pm 0.04 & 36 \\ \text { Forepaw-hindpaw } & 1.70 \pm 0.03 & 2.28 \pm 0.04 & 34 \\ \text { Hindpaw-PMBSF } & 2.72 \pm 0.03 & 3.38 \pm 0.04 & 24\end{array}$



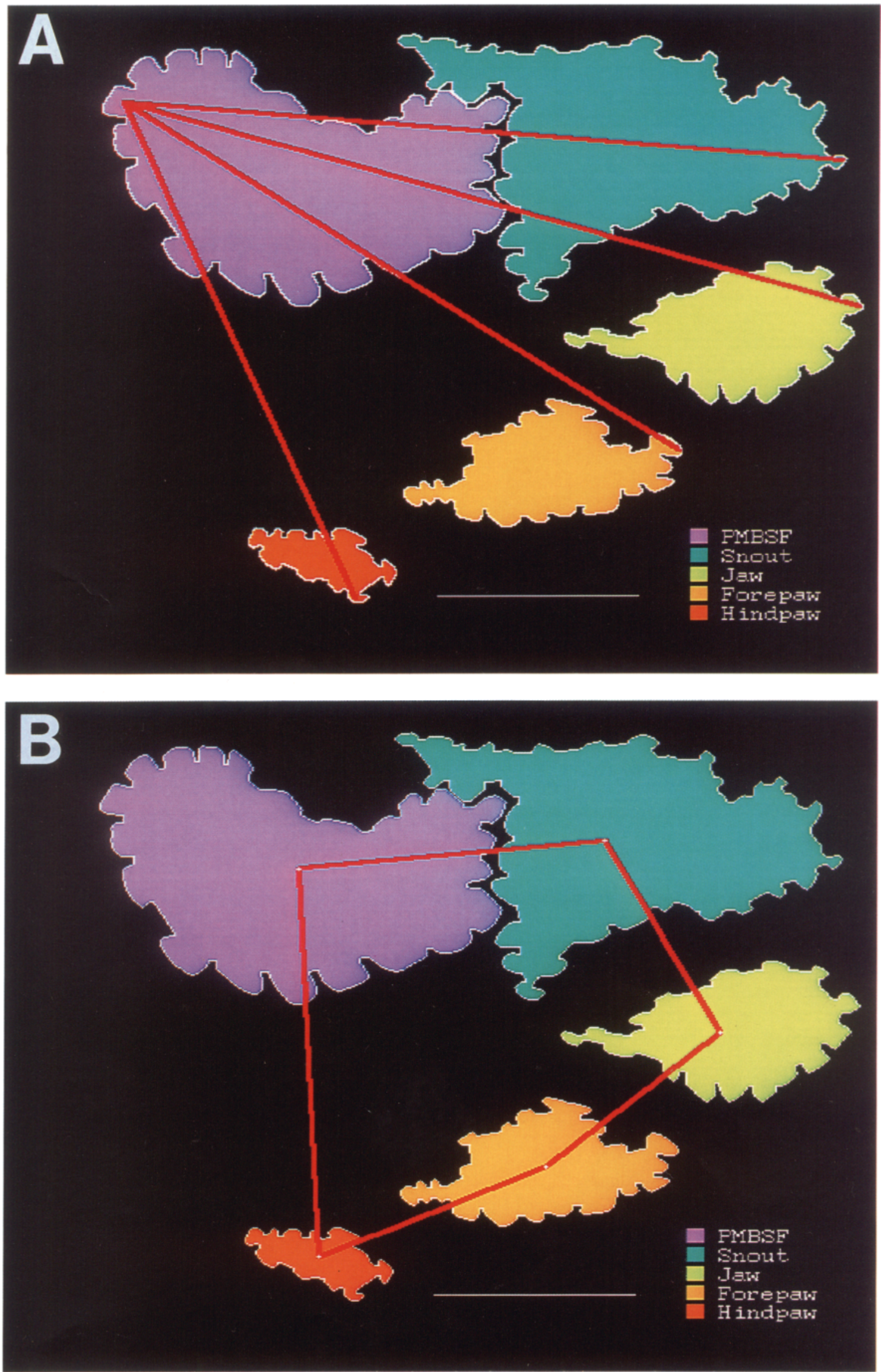

Figure 11. Linear measurements of SI in juvenile and adult rats. A, Four standard vectors were used to measure the extent of SI in neonatal and adult cortices. In each case, the lines originate from the center of the Al barrel and extend, respectively, to the most anterior barrel in the head, lower jaw, and forepaw representations, and the most medial barrel in the hindpaw representation. B, Lines connecting the centers of mass (centroids) of each of the five major representations in SI. Scale bars, $2 \mathrm{~mm}$. 

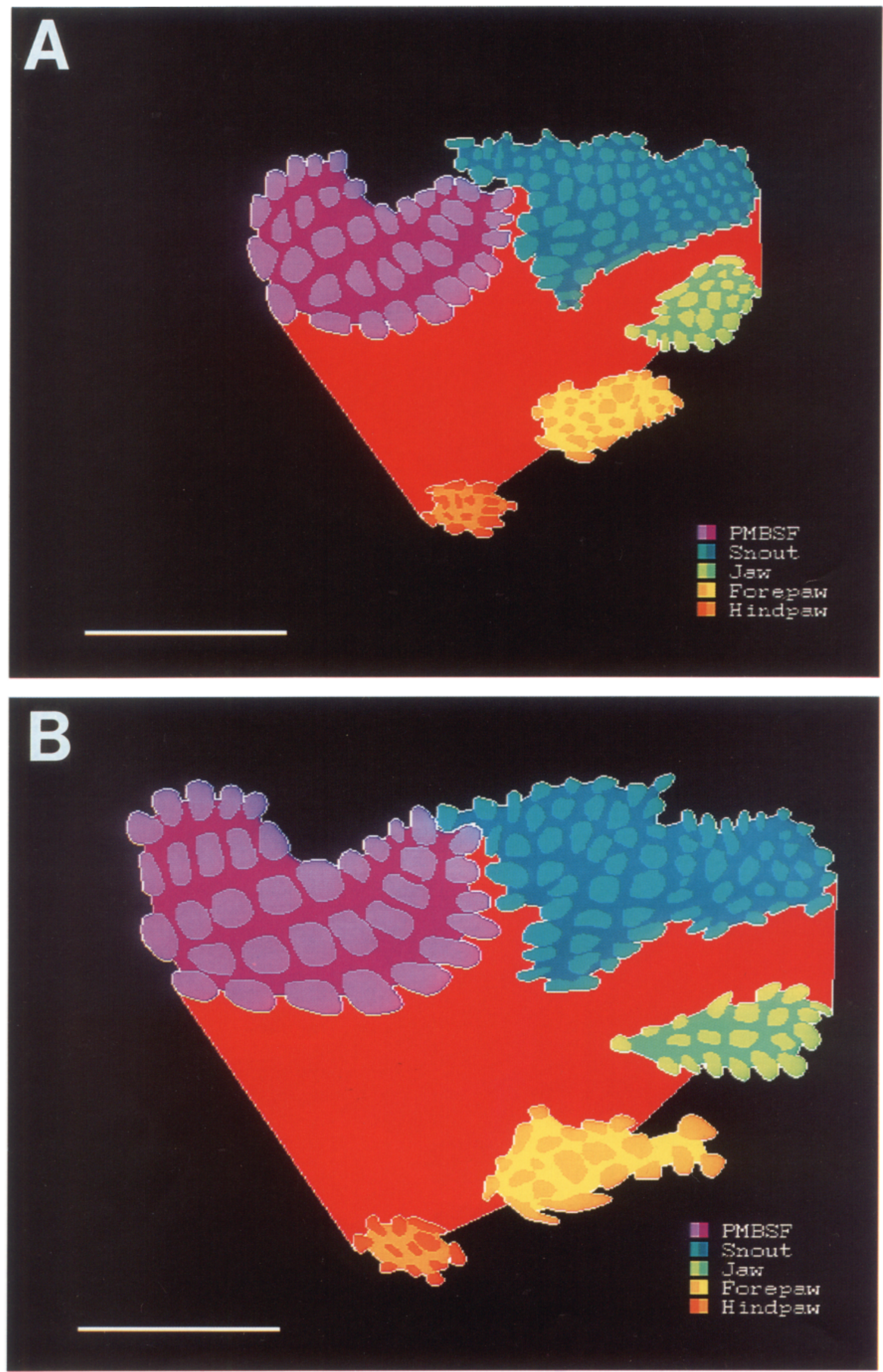

Figure 12. Juvenile and adult SI maps in representative animals showing overall change in the size of SI during postnatal maturation. $A$, Juvenile map (1-week-old animal). B. Adult map (11-week-old animal; representation as in Fig. 4). Notice that whereas the overall growth of SI is readily apparent, the differential growth of its component parts is not; these differences can be brought out only by detailed measurement. Scale bars, $2 \mathrm{~mm}$. 

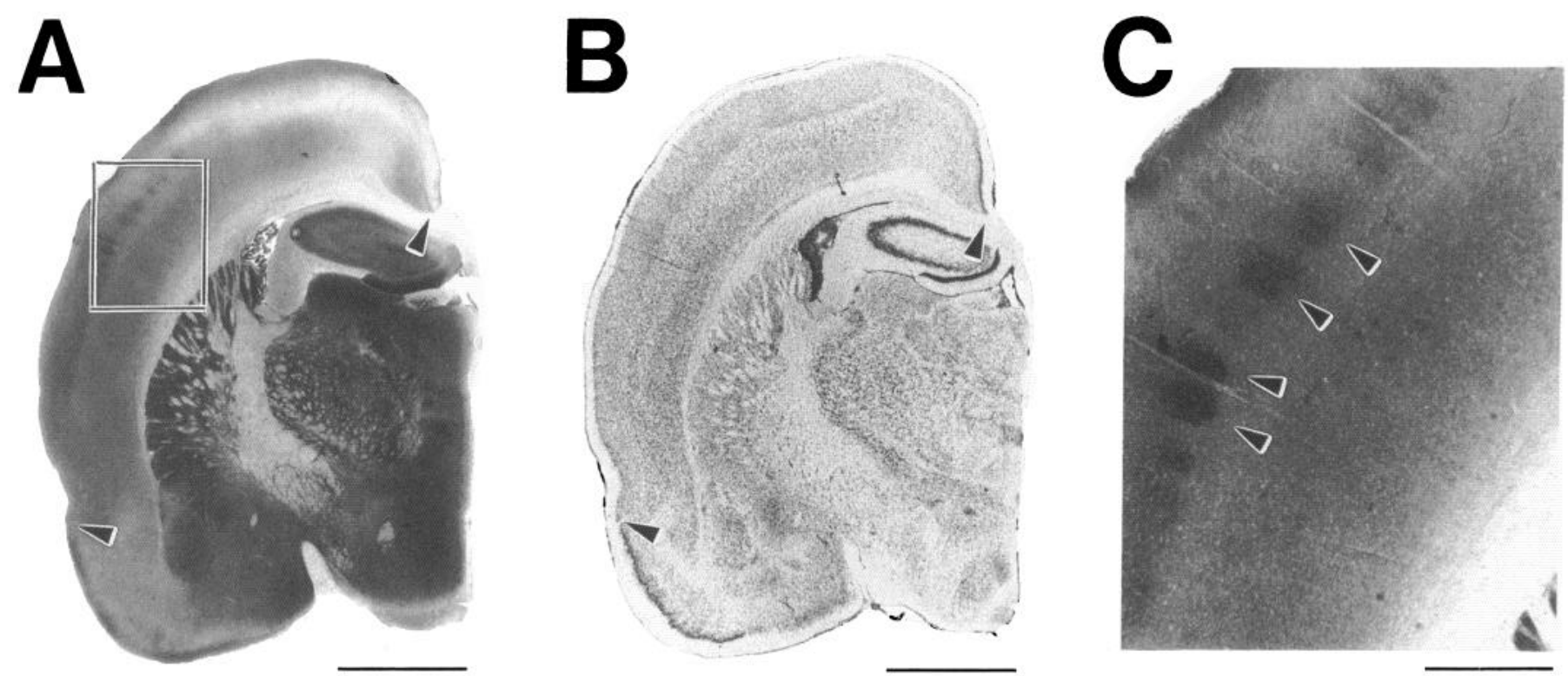

Figure 13. Definition of the neocortex in coronal sections. A, Low-power view of $50-\mu$ m-thick section at the level of the anterior pole of the hippocampus (SDH stained). Arrowheads indicate the rhinal fissure laterally and the termination of the cingulate cortex medially; these boundaries were used to define the linear extent of the neocortex in each section. $B$, Section stained with cresyl violet; these sections were used to confirm neocortical boundaries in SDH-stained sections (compare $A$ ). Higher-power view of $A$ showing barrels in coronal section (arrowheads). Although barrels are easily seen in this orientation, their overall pattern cannot be reconstructed precisely, as can be done readily in the flattened cortex (see Materials and Methods). We could, however, use such sections to estimate the average growth of SI and barrels in this plane of section (see text). Scale bars: $A$ and $B, 2 \mathrm{~mm} ; C, 0.5 \mathrm{~mm}$.

rest of neocortex is of particular interest because of the salient role of somatic sensation in the normally nocturnal rat.

\section{Some implications}

In many mammals, the primary visual, auditory, and somatic sensory cortices stand out as regions that stain more intensely with metabolic markers such as $\mathrm{SDH}, \mathrm{CO}$, and 2-deoxyglucose (Sokoloff, 1978; Kaas, 1983; Killackey, 1983). In keeping with these observations, the vascularization of the cortex varies from region to region, presumably reflecting differences in the metabolic demand of different functional areas (Borowsky and Collins, 1989; Zheng et al., 1991). Barrels and other iterated telencephalic units (e.g., blobs in VI, glomeruli in the olfactory bulb) are also defined by their greater metabolic and/or electrical activity. Such modules stain more intensely with markers for metabolically important enzymes such as $\mathrm{CO}$ or SDH (Horton, 1984; Hendrickson, 1985; Dawson and Killackey, 1987; Wallace, 1987), and may be revealed by more direct metabolic indicators of electrical activity, such as 2-deoxyglucose (Sokoloff, 1978; McCasland and Woolsey, 1988). Moreover, at least some cortical modules are more richly vascularized than the surrounding cortex (Patel, 1983; Zheng et al., 1991). In the present study, we note that the areas within SI that grow most are generally the same regions that show higher levels of enzymatic staining and vascularization. An interesting possibility, therefore, is that the greater metabolic and/or electrical activity of these subregions of the cortex promotes the local growth of neuropil.

In the light of this suggestion, an important question concerns the significance of SDH reactivity. SDH is a mitochondrial enzyme that catalyzes the conversion of succinate to fumarate in the citric acid cycle and that participates in the electron transport chain. It has been used as a metabolic marker in the musculoskeletal system, and is present in increased amounts in muscle fibers that have higher rates of electrical activity (Burke, 1983).
Furthermore, motor neurons that innervate more active muscle fibers are themselves richer in oxidative enzymes than other motor neurons (Sickles and Oblak, 1984). Although the use of SDH staining in the nervous system has been largely as a qualitative histochemical technique, the regions of the brain that stain most intensely with SDH are, by and large, those that have high levels of neural activity, most notably the primary auditory, visual, and somatosensory cortices and the related thalamic and subthalamic nuclei. That these SDH-positive brain regions are metabolically more active than many other areas of the CNS is supported by the observation that the same structures stain with markers for mitochondrial electron transport enzymes, such as $\mathrm{CO}$, and show greater uptake of 2-deoxyglucose (Durham and Woolsey, 1977, 1978; Wong-Riley and Welt, 1980; Carroll and Wong-Riley, 1984; McCasland and Woolsey, 1988). Nevertheless, the case for greater metabolic and/or electrical activity of modules such as barrels compared to adjacent cortical regions remains circumstantial and must be validated by more specific experiments.

Other explanations of differential cortical growth must, of course, be considered. One possibility is that the differential brain growth we have observed is not related to postnatal function, but arises from some inherent property of different brain

$\begin{aligned} & \text { Table 9. Average growth of the neocortex as a whole compared to } \\
& \text { the average areal growth of SI }\end{aligned}$
\begin{tabular}{lllll}
$\begin{array}{l}\text { Number of } \\
\text { hemispheres } \\
\text { examined } \\
\text { juveniles/ } \\
\text { adults) }\end{array}$ & Juvenile & Cortical area $\left(\mathrm{mm}^{2}\right)$ & & \\
\cline { 3 - 5 } & $55 / 57$ & $12.50 \pm 0.23$ & $22.82 \pm 0.39$ & $83 \%$ \\
SI & $61 / 43$ & $107.9 \pm 1.3$ & $187.0 \pm 1.5$ & $73 \%$ \\
Neocortex & & & & \\
\hline
\end{tabular}


regions. The merits of this idea can be tested experimentally by diminishing or augmenting metabolic and/or electrical activity and observing the effect on cortical growth. Because barrels and other iterated units in layer IV of sensory cortices are specifically related to input from subcortical relays, another possibility is that greater growth is a specific consequence of thalamic innervation. We note, however, that a correlation of growth and thalamic input is consistent with an activity-dependent modulation of neuropil growth: regions directly innervated by thalamic afferents are likely to be more active than cortical regions less immediately related to sensory receptors.

Finally, the regional differences in postnatal cortical growth that we have described in the rat are relatively small (up to twofold). The magnitude of these differences, however, should not obscure their potential importance. Differential cortical growth of even a few percent may be highly significant in the context of circuitry generated in response to experience.

\section{References}

Bedi KS, Warren MA (1988) Effects of nutrition on cortical development. In: Cerebral cortex, Vol 7, Effects of nutrition on cortical development (Peters A, Jones EG, eds), pp 441-478. New York: Plenum.

Belford GR, Killackey HP (1980) The sensitive period in the development of the trigeminal system of the neonatal rats. J Comp Neurol 193:335-350.

Borowsky IW, Collins RC (1989) Metabolic anatomy of brain: a comparison of regional capillary density, glucose metabolism, and enzyme activities. J Comp Neurol 288:401-413.

Burke RE (1983) Motor units: anatomy, physiology, and functional organization. In: Handbook of physiology-the nervous system II, (Brooks VB, ed), pp 345-422. Bethesda, MD: American Physiological Society.

Carroll EM, Wong-Riley MTT (1984) Quantitative light and electron microscopic analysis of cytochrome oxidase-rich zones in the striate cortex of the squirrel monkey. J Comp Neurol 222:1-17.

Cravioto J, De Licardie ER, Birch HG (1966) Nutrition, growth and neurointegrative development: an experimental and ecologic study. Pediatrics 38:319-372.

Dawson DR, Killackey HP (1987) The organization and mutability of the forepaw and hindpaw representations in the somatosensory cortex of the neonatal rat. J Comp Neurol 256:245-256.

Dawson DR, Wall JT, Kaas JH, Killackey HP (1987) Internal organization of anatomical and physiological representation of the forepaw in rat somatosensory cortex. Soc Neurosci Abstr 13:248.

Dekaban AS, Sadowsky D (1978) Changes in brain weights during the span of human life: relation of brain weight to body heights and body weights. Ann Neurol 4:345-356.

DeLong GR, Robbins J, Condliffe G (1989) Iodine and the brain. New York: Plenum

Durham D, Woolsey TA (1977) Barrels and columnar cortical organization: evidence from 2-deoxyglucose (2-DG) experiments. Brain Res 137:169-174.

Durham D, Woolsey TA (1978) Acute whisker removal reduces neuronal activity in barrels of mouse SmI cortex. I Comp Neurol 178: 629-644.

Greenough WT, Chang F-LF (1988) Dendritic pattern formation involves both oriented regression and oriented growth in the barrels of mouse somatic sensory cortex. Dev Brain Res 43:148-152.

Hendrickson AE (1985) Dots, stripes and columns in monkey visual cortex. Trends Neurosci 7:406.

Horton JC (1984) Cytochrome oxidase patches: a new cytoarchitectonic feature of monkey visual cortex. Philos Trans R Soc Lond [Biol] 304:199.

Jensen KF, Killackey HP (1987) Terminal arbors of axons projecting to the somatosensory cortex of the adult rat. I. The normal morphology of specific thalamocortical afferents. J Neurosci 7:3529-3543.

Johnson JI (1990) Comparative development of somatic sensory cortex. In: Cerebral cortex, vol 8 (Jones EG, Peters A, eds), pp 385-449. New. York: Plenum.
Kaas JH (1983) What, if anything, is SI? Organization of first somatic sensory area of cortex. Physiol Rev 63:206-231.

Killackey HP (1983) The somatosensory cortex of rodent. Trends Neurosci 6:425-429.

Killackey HP, Belford GR (1979) The formation of afferent patterns in the somatic sensory cortex of the neonatal rat. J Comp Neurol 183: 285-304.

Koralek K-A, Olavarria J, Killackey HP (1990) Areal and laminar organization of corticocortical projections in the rat somatosensory cortex. J Comp Neurol 299:133-150.

Lorente de No R (1922) La corteza cerebral del ratón. Trab Lab Invest Biol 20:41-78.

McCasland JS, Woolsey TA (1988) High-resolution 2-deoxyglucose mapping of functional cortical columns in mouse barrel cortex. J Comp Neurol 278:555-569.

Nachlas MM, Tsou KC, DeSousa E, Cheng CH, Seligman AM (1957) Cytochemical demonstration of succinic dehydrogenase by the use of a new $p$-nitrophenyl substituted ditctrazolc. J Histochem Cytochem 5:420-436.

Pakkenberg H, Voigt J (1964) Brain weight of the Danes. Acta Anat (Basel) 56:297-307.

Patel U (1983) Non-random distribution of blood vessels in the posterior region of the rat somatosensory cortex. Brain Res 289:65-70.

Peinado A, Katz LC (1990) Development of cortical spiny stellate cells: retraction of a transient apical dendrite. Soc Neurosci Abstr 16: 1127.

Pomeroy SL, LaMantia AS, Purves D (1990) Postnatal construction of neural circuitry in the mouse olfactory bulb. J Neurosci 10:19521966.

Rice FL (1985) Gradual changes in the structure of the barrels during maturation of the primary somatosensory cortex in the rat. J Comp Neurol 236:496-503.

Rice FL, Van der Loos H (1977) Development of the barrels and barrel field in the somatic sensory cortex of the mouse. J Comp Neurol 171:545-560.

Rice FL, Gomez C, Barstow C, Burnet A, Sands P (1985) A comparative analysis of the development of the primary somatosensory cortex: interspecies similarities during barrel and laminar development. J Comp Neurol 236:477-495.

Sickles DW, Oblak TG (1984) Metabolic variation among alpha-motoneurons innervating different muscle fiber types. I. Oxidative enzyme activity. J Neurophysiol 41:529-537.

Sokoloff L (1978) Metabolic probes of central nervous system activity in experimental animals and man. Sunderland, MA: Sinauer.

Tuttle L, Satterly L (1925) Theory of measurement, Chap 22, pp 290297. London: Longmans.

Vongdokmai R (1980) Effect of protein malnutrition on development of mouse cortical barrels. J Comp Neurol 191:283-294.

Wallace MN (1987) Histochemical demonstration of sensory maps in the rat and mouse cerebral cortex. Brain Res 418:178-182.

Welker C (1971) Microelectrode delineation of fine grain somatotopic organization of SmI cerebral neocortex in albino rat. Brain Res 26: 259-275.

Welker W, Sanderson KJ, Shambes GM (1984) Patterns of afferent projections to transitional zones in the somatic sensorimotor cerebral cortex of albino rats. Brain Res 292:261-267.

Wong-Riley MTT (1989) Cytochrome oxidase: an endogenous metabolic marker for neuronal activity. Trends Neurosci 12:94-101.

Wong-Riley MTT, Welt C (1980) Histochemical changes in cytochrome oxidase of cortical barrels after vibrissal removal in neonatal and adult mice. Proc Nat Acad Sci USA 77:2333-2337.

Woolsey TA (1985) Structural, functional and biochemical plasticity in the rodent brain. Pontificiae academie scientarium scripta varia 59 (Working group on: Developmental neurobiology of mammals), pp 347-380.

Woolsey TA, Van der Loos H (1970) The structural organization of layer IV in the somatic sensory region (SI) of mouse cerebral cortex. Brain Res 17:205-242.

Woolsey TA, Durham D, Harris RM, Simon DJ, Valentino KL (1981) Somatosensory development. Dev Percept 1:259-292.

Theng D, LaMantia AS, Purves D (1991) Specialized vascularization of the primate visual cortex. J Neurosci 11:2622-2629. 